\title{
The Energetics of Entrainment Across a Density Interface ${ }^{1}$
}

\author{
Roland B. STULI ${ }^{2}$ \\ Department of Atmospheric Sciences, University of Washington, Seatlle 98195 \\ (Manuscript received 10 October 1975, in revised form 29 March 1975)
}

\begin{abstract}
A theory of the fluid entrainment rate into a turbulent, mixed layer across a horizontal density interface is presented. By integrating the turbulent kinetic energy equation over the depth of the mixed layer and assuming that turbulence dissipation rates are proportional to production rates, an equation is derived relating the potential energy change and entrainment rate to four major terms: 1) buoyant production of energy due to heating at the earth's surface; 2) mechanical production due to wind shear at the earth's surface; 3) mechanical production due to wind shear and dynamic instabilities such as Kelvin-Helmholtz waves at the inversion interface; and 4) energy losses due to internal gravity waves. It is shown that most previously published theories are just special cases of this more general energetics theory.
\end{abstract}

\section{Introduction}

Turbulent mixed layers often occur in nature which are bounded above or below by a density interface. On the opposite side of this interface is a layer of nonturbulent, often stably stratified fluid. In the atmosphere this situation is that of a temperature inversion capping the boundary layer. The thickness of the mixed layer is controlled by the rate of entrainment of fluid across this density interface, by the net divergence of fluid from the mixed layer, and by advective effects, assuming an incompressible fluid. A diagnostic equation is derived here for the entrainment rate which can be used to yield a predictive equation for the mixed layer thickness. Although emphasis is placed on an atmospheric environment, the results are also applicable to some oceanic situations.

The mixed layer thickness is required for determining the concentrations of variables within, and the fluxes of variables across, the boundary layer. Hence, knowledge of the entrainment rate is important for pollution budget studies, for forecast and general circulation model boundary conditions, for heat island and dryline problems, and for cloud-subcloud layer interaction studies, for example.

Various proposals for determining the entrainment rate have been made in the past, ranging from simple thermodynamic considerations to complex numerical models (Rouse and Dodu, 1955; Ball, 1960; Fleagle

\footnotetext{
1 Contribution No. 376, Department of Atmospheric Sciences, University of Washington.

2 Present affiliation: Air Force Global Weather Central, Offutt AFB, Omaha, Neb. 68113 .
}

and Businger, 1963; Kraus and Turner, 1967; Lilly, 1968; Geisler and Kraus, 1969; Miropol'skiy, 1970; Stull, 1973; Tennekes, 1973; Carson, 1973; Betts, 1973, 1974; Deardorff, 1973, 1974a, b; Pollard et al. 1973; Wyngaard and Coté, 1974; Drake et al., 1975; Niiler, 1976.) In this work, the primary hypothesis is that the rate of potential energy change associated with turbulent entrainment is related to the net rate of turbulent kinetic energy production in the mixed layer.

Some laboratory experiments simulating turbulent entrainment have been reported in the literature with enlightening photographs of the entrainment (Deardorff et al., 1969; Turner, 1968b; Baines, 1975). In general, the following qualitative results are observed:

1) Entrainment occurs in only one direction across the density interface-into the turbulent region.

2) The interface is contorted by the turbulence and penetrative convection in the mixed layer.

3) The entrainment of fluid, as observed using dye, is intimately connected with the turbulent elements that interact with the interface.

4) The interface, although contorted, is very sharp when there is entrainment across it.

5) Internal gravity waves are excited in the nonturbulent region by the penetrative turbulence.

A summary of the quantitative results of many more laboratory experiments is given in Section 4.

\section{Turbulent kinetic energy}

Applied to an atmospheric boundary layer with no liquid water present, the equation of turbulent kinetic 
energy (TKE) is (Lenschow, 1974)

$$
\begin{aligned}
& \frac{\overline{d q^{2}}}{d t}+\frac{\partial}{\partial Z} \overline{w^{\prime}}\left(\frac{p^{\prime}}{\rho_{0}}+q^{2}\right)=\frac{\tau}{\rho_{0}} \cdot \frac{\partial \mathbf{u}}{\partial Z}+\frac{g}{\theta_{v 0}} \overline{w^{\prime} \theta_{v}^{\prime}} \quad-\epsilon \\
& \begin{array}{llll}
\text { Storage } & \begin{array}{l}
\text { Pressure } \\
\text { and }
\end{array} & \begin{array}{l}
\text { Mechanical } \\
\text { correlation }
\end{array} & \begin{array}{l}
\text { Buoyant } \\
\text { production }
\end{array}
\end{array} \\
& \text { and } \begin{array}{lll}
\text { correlation } & \text { production production dissipation }
\end{array} \\
& \text { of TKE } \quad \text { transport } \\
& \text { of TKE }
\end{aligned}
$$

Here $\overline{q^{2}}$ is the TKE per unit mass, i.e.,

$$
\overline{q^{2}}=\frac{1}{2} \overline{\left(u^{\prime 2}+v^{\prime 2}+w^{\prime 2}\right)}=\mathrm{TKE} \mathrm{m}^{-1}
$$

$p$ is pressure, $\tau$ the shear stress vector, $\mathbf{u}$ wind velocity, $\epsilon$ the viscous dissipation, $\theta_{v}$ the virtual potential temperature (used as a measure of the density), $g$ the acceleration due to gravity, $w$ the vertical velocity, $t$ time, $\rho$ density, and $m$ mass; the overbars indicate mean values, the primes perturbation components, and the subscript 0 means environmental conditions.

Eq. (1) can be integrated over the depth $Z_{B L}$ of the boundary layer to give an equation of the turbulent kinetic energy per unit area (TKE $\mathrm{A}^{-1}$ ), i.e.,

$$
\text { TKE A }{ }^{-1}=\rho_{0} \int_{0}^{Z_{B L}} \overline{q^{2}} d Z,
$$

where the density is assumed to be approximately constant. Hence, each term of (1), multiplied by density and integrated over the depth of the boundary layer, is examined individually below.

Integrating the pressure correlation and eddy transport term yields

$$
\rho_{0} w^{\prime} \overline{\left(\frac{p^{\prime}}{\rho_{0}}+q^{2}\right)_{Z_{B L}}}
$$

neglecting the pressure correlation at the ground and assuming that there is no eddy transfer of TKE down through the earth's surface. This term can be non-zero if vertically propagating gravity waves are excited in the stable fluid above the interface by the penetrative convection and turbulence from the mixed layer.

Next, splitting the integral of the buoyant production term into two parts yields

$$
\frac{\rho_{0} g}{\theta_{v 0}} \int_{0}^{Z_{1}} \overline{w^{\prime} \theta_{v}^{\prime}} d Z+\frac{\rho_{0} g}{\theta_{v 0}} \int_{Z_{1}}^{Z_{B L}} \overline{w^{\prime} \theta_{v}^{\prime}} d Z,
$$

where $Z_{1}$ is the level of zero heat flux (see Fig. 1). But it can easily be shown that

$$
\frac{\rho_{0} g}{\theta_{v 0}} \int_{Z_{1}}^{z_{B L}} \overline{w^{\prime} \theta_{o}^{\prime}} d Z=-\frac{d V}{d t}
$$

where $V$ is the potential energy per unit area due to turbulent entrainment. Hence, the buoyant production term becomes

$$
\frac{\kappa_{0} g}{\theta_{v 0}} \int_{0}^{Z_{1}} \overline{w^{\prime} \theta_{v}^{\prime}} d Z-\frac{d V}{d t}
$$

Combining the integrals of the storage and dissipation terms yields

$$
L \equiv \int_{0}^{Z_{B L}}\left(\epsilon+\frac{d q^{2}}{d l}\right) d Z,
$$

where one interprets $L$ as a loss term due to viscous dissipation, storage and advection of TKE from the area of interest.

Rewriting (1) now gives

$$
\begin{aligned}
\frac{d V}{d t}=\frac{\rho_{0} g}{\theta_{v 0}} \int_{0}^{Z_{1}} \overline{w^{\prime} \theta_{v}^{\prime}} d Z+\int_{0}^{Z_{B L}} & \frac{\partial \mathrm{u}}{\partial Z} d Z \\
& -\rho_{0} w^{\prime}\left(\frac{p^{\prime}}{\rho_{0}}+q^{2}\right)_{Z_{B L}}-\rho_{0} L .
\end{aligned}
$$

This is the general result that was sought. It states that the TKE generated buoyantly and mechanically in a volume, which is not otherwise dissipated or lost out of the boundaries, ends up as an increase in the potential energy of that volume.

\section{Entrainment velocity for a model atmosphere}

The general result just derived is now applied to a specific slab-like model atmosphere, to obtain an expression for the entrainment velocity.

\section{a. The model atmosphere}

Fig. 1 shows a picture of the model boundary layer along with the idealized profiles of temperature, heat flux, humidity and wind. Sketched in Fig. 1a is a stable layer of air overlying a well-mixed, turbulent layer. The interface between these two layers is contorted due to the turbulent eddies present in the mixed layer. But the mean level of this interface is defined as the inversion base height $h$. If the height of the boundary layer is defined as the height at which surface-based effects are still dominant (not including gravity waves), then this height is defined as the top of the contorted interface. The distance between the top $Z_{B L}$ of the boundary layer and the mean interface height $h$ is just the overshoot distance $d$ of the plumes or eddies. The average lower limit of the contorted interface is defined as $Z_{3}$.

Assuming that the turbulent layer is very well mixed from the earth's surface up to the mean inversion height implies that the potential temperature and moisture are constant with height over this region. Idealizing the inversion by a step discontinuity in temperature and humidity results in the virtual potential tempera- 


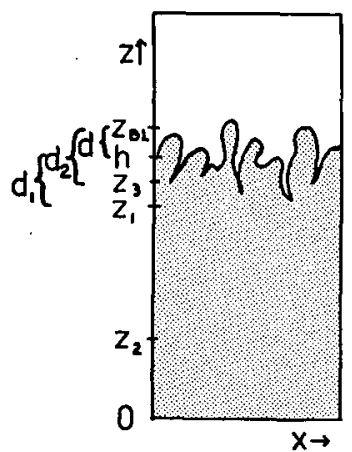

(a)

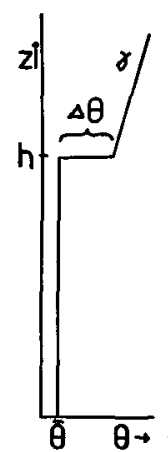

(b)

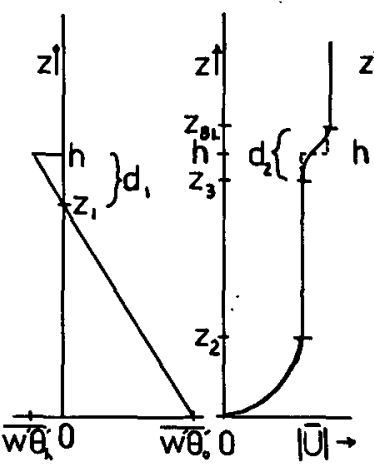

(d)

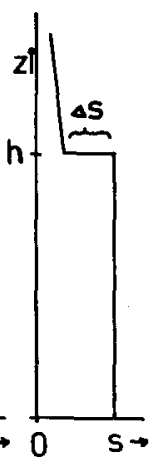

(e)

FIG. 1. The idealized model boundary layer showing a vertical cross section (a), the virtual potential temperature profile (b), the heat flux profile (c), the mean wind profile (d), and the profile of a scalar such as humidity (e).

ture profile shown in Fig. 1b, with a virtual potential temperature step of $\Delta \theta_{v}$ at the inversion. Above the step is a region with stable lapse rate $\gamma$. Any scalar $s$, such as humidity or pollutants, has a profile as sketched in Fig. 1e, assuming the major source of those tracers is at or near the earth's surface.

If the shape of the temperature profile in the mixed layer is constant with time as it warms, then the heat flux in this mixed layer is linear with height. Warm air at the inversion interface that is entrained downward into the mixed layer implies a downward (negative) heat flux at $h$. If there is no heating or cooling of air above $h$, as assumed here, then the heat flux is zero above $h$. Thus, if the mixed layer is warmed by the combined effects of entrainment at the inversion and solar heating of the earth's surface, then the heat flux is linear between the extreme values of negative heat flux at $h$ and positive heat flux at $Z=0$ (see Fig. 1c). We define the level of zero heat flux between 0 and $h$ as $Z_{1}$, and the region of negative heat flux as $d_{1}=h-Z_{1}$. For no surface heating $d_{1}=h$; for no entrainment $Z_{1}=h$ $\left(d_{1}=0\right)$.

The mean wind profile is idealized as is shown in Fig. 1d.. A logarithmic wind profile modified by stability is idealized in the surface layer, where $Z_{2}$ is the top of this surface layer. Between $Z_{2}$ and $Z_{3}$ the wind. shear is near zero. Between $Z_{3}$ and $Z_{B L}$ is the region $\left(d_{2}=Z_{B L}-Z_{3}\right)$ where the mean wind recovers to its geostrophic value at the top of the boundary layer. The shape of the wind profile need not be specified within $d_{2}$; because only the magnitude of the velocity difference between $Z_{B L}$ and $Z_{3}$ is used in the entrainment model here. Depending on the situation modeled, a velocity jump could exist at $h$ where $Z_{3}=h=Z_{B L}$, or the surface layer could extend to near the inversion interface where $Z_{2}=Z_{3}$, or surface layer effects could be negligible for which $Z_{2} \approx 0$.

Each term of (3) will now be simplified based on this model atmosphere.

\section{b. Potential energy term}

For a linear heat flux profile as sketched in Fig. 1c,

$$
\left.\frac{d V}{d t}=-\frac{\rho_{0} g}{\theta_{v 0}} \int_{Z_{1}}^{h} \overline{w^{\prime} \theta_{v}^{\prime}} d Z=-\frac{\rho_{0} g}{\theta_{v 0}} \frac{d_{1}}{2} \overline{\left(w^{\prime} \theta_{v}^{\prime}\right.}\right)_{h}
$$

But the heat flux due to entrainment at $h$, for this case, is

$$
\left.\overline{\left(w^{\prime} \theta_{v}^{\prime}\right.}\right)_{h}=-w_{e} \Delta \theta_{v}
$$

where $w_{e}$ is the entrainment velocity (time rate of volume entrained per unit area). Hence,

$$
\frac{d V}{d t}=\frac{\rho_{0}}{2}\left(\frac{\Delta \theta_{v}}{\theta_{v 0}}\right) g d_{1} w_{e}
$$

\section{c. Buoyant generation term}

For a linear heat flux profile this term becomes

$$
\left.\frac{\rho_{0} g}{\theta_{v 0}} \frac{Z_{1}}{2} \overline{\left(w^{\prime} \theta_{v}^{\prime}\right.}\right)_{s}
$$

where $\left(\overline{w^{\prime} \theta_{v}^{\prime}}\right)_{s}$ is the turbulent heat flux at the earth's surface. Rewriting this in terms of $w_{*}$, the free convection scaling velocity, yields

$$
\frac{\rho_{0}}{2}\left(\frac{Z_{1}}{h}\right) e_{*}^{3}
$$

where

$$
\left.w_{*}^{3} \equiv \frac{g h}{\theta_{v 0}} \overline{\left(w^{\prime} \theta_{v}^{\prime}\right.}\right)_{s}
$$

\section{d. Mechanical generation term}

This integral term is split into three segments, corresponding to the surface layer (I), the region of near constant wind velocity (II), and the region at the inter- 
face (III). If shear stress in the surface layer is assumed to be roughly constant with height, then

$$
\mathrm{I}=\rho_{0} u_{*}^{2} \hat{u}
$$

where $\hat{u}$ is the wind magnitude at the top of the surface layer and $u_{*}$ the friction velocity. Note that in this simplified slab model, the wind speed in the region of II, the average wind speed over the mixed layer depth, and $\hat{u}$ are nearly equal. If flux profile relationships in the surface layer are known (e.g., Businger et al., 1971; Dyer, 1974), then $\hat{u}$ can be rewritten as a function of $u_{*}$.

Term II is zero because the wind shear is zero in that region (see Fig. 1).

It is hypothesized that

$$
\mathrm{III}=a_{3} \rho_{0}\left(\Delta u_{h}\right)^{3},
$$

where $a_{3}$ is a constant of proportionality and $\Delta u_{h}$ is the magnitude of wind velocity change across the interface. In essence, this hypothesis combines

$$
\tau_{h}=\rho_{0} w_{e} \Delta u_{h} \text { and } \frac{d u}{d Z} \propto \frac{\left(\Delta u_{h}\right)^{2}}{w_{e} d_{2}} .
$$

This expression for the wind shear, rather than the surface layer mixing length or $K$ theory approach, is used because of the agreement with the data of Ellison and Turner (1959), Lofquist (1960), Moore and Long (1971) and Thorpe (1973), as discussed in the next section. This term includes contributions from dynamic instabilities such as Kelvin-Helmholz waves.

The total mechanical generation term is

$$
\rho_{0} u_{*}^{2} \hat{u}+\rho_{0} a_{3}\left(\Delta u_{h}\right)^{3} \text {. }
$$

\section{e. Gravity wave term}

Correlations $\overline{w^{\prime} p^{\prime}}$ and $\overline{w^{\prime} q^{2}}$ are possible for internal gravity waves with a vertical component of group velocity (Jones, 1969). If traditional linear wave theory is used to describe these waves, then $\overline{w^{\prime} q^{2}}$ is assumed to be negligible. We abbreviate this term as

$$
\overline{w^{\prime} p^{\prime}} \equiv \mathrm{Gi}
$$

to denote the energy loss rate due to internal gravity waves. An approximation for this term is made in a companion paper (Stull, 1976a).

\section{f. Loss term}

Deardorff et al. (1969) found that roughly $98 \%$ of the TKE generated in a free convection laboratory tank experiment is lost due to dissipation or storage. In general, the time scales of dissipation are much shorter than the turnover time of plumes in the convective boundary layer; hence, dissipation can be assumed to be in quasi-steady state. In a steady-state energy spectrum, the dissipation rate is equal to the production rate of TKE. Hence, for this quasi-steady-state situation in which only a small fraction of the total energy is not dissipated, the assumption that the dissipation rate is proportional to the production rate should not be too poor.

Extending this argument to include mechanically generated TKE, this term is approximated as

$$
b_{1}\left[\frac{1}{2} \rho_{0} Z_{1} w_{*}^{3} h^{-1}\right]+b_{2}\left[\rho_{0} u_{*}^{2} \hat{u}\right]+b_{3}\left[\rho_{0} a_{3}\left(\Delta u_{h}\right)^{3}\right] \text {, }
$$

where $b_{i}$ are the constants of proportionality. The choice of values of $b_{i}$ are crucial in obtaining the proper entrainment velocity because the entrainment is found to be the very small difference between the large terms of production and dissipation. Unfortunately, no theoretical estimate for the values of $b_{i}$ has been made, and there is a large uncertainty in the empirically found values (see Section 5). Thus the constants $b_{i}$ are treated as unknowns. A trial and error scheme to evaluate these constants is discussed in Section 5.

\section{g. Entrainment velocity}

Combining these approximations for each term yields

$$
w_{e}=\frac{2 \theta_{v 0}}{g d_{1} \Delta \theta_{v}}\left[c_{1} w_{*}^{3}+c_{2} u_{*}^{3}+c_{3}\left(\Delta u_{h}\right)^{3}-\mathrm{GW}\right],
$$

where the Businger-Dyer (Businger et al., 1971) fluxprofile relation as integrated by Paulson (1970) has been used to give $c_{2}$. Alternate forms of this equation are

$$
\begin{aligned}
& w_{e}=\frac{2 \theta_{v 0}}{g d_{1} \Delta \theta_{v}}\left[c_{1} w_{*}^{3}+\left(1-b_{2}\right) u_{*}^{2} \hat{u}+c_{3}\left(\Delta u_{h}\right)^{3}-\mathrm{GW}\right], \\
& w_{e}=A_{1} \frac{\left(\overline{w^{\prime} \theta_{v}^{\prime}}\right)_{s}}{\Delta \theta_{v}}+A_{2} \frac{\theta_{v 0}\left(u_{*}^{2} \hat{u}\right)}{g d_{1} \Delta \theta_{v}}+A_{2} \frac{\Delta u_{h}}{\operatorname{Ri}_{B}}-\frac{2 \theta_{v 0}(\mathrm{GW})}{g d_{1} \Delta \theta_{v}},
\end{aligned}
$$

where the various coefficients are

$$
\left.\begin{array}{c}
A_{1}=\left(1-b_{1}\right)^{\frac{3}{3}}, \quad A_{2}=2\left(1-b_{2}\right), \quad A_{3}=2 a_{3}\left(1-b_{3}\right) \\
c_{1}=\frac{1}{2}\left(1-b_{1}\right) \frac{Z_{1}}{h}, c_{2}=k^{-1}\left(1-b_{2}\right)\left[\ln \left(Z_{2} / Z_{0}\right)-\psi\right], \\
c_{3}=a_{3}\left(1-b_{3}\right) \\
\operatorname{Ri}_{B}=\frac{g\left(\Delta \theta_{v} / \theta_{v 0}\right) d_{1}}{\left(\Delta u_{h}\right)^{2}}
\end{array}\right\} .
$$

Here $\psi$ is a stability correction factor, $k$ the von Kármán constant $(\sim 0.35)$ and $Z_{0}$ the roughness length.

Form (7) is recommended here as being the most accurate and easiest to use. For future reference, the entrainment velocity equations are referred to as the "energetics theory" or the "energetics equations." Although these three forms of the energetics equations 
TABLE 1. Published values of the heat flux ratio $A_{1}$. The type of published value is classified as either experimentally observed $(\mathrm{O})$ or theoretically assumed $(\mathrm{T})$.

\begin{tabular}{|c|c|c|c|c|c|}
\hline$A_{1}$ & Investigator & Year & Journal & Type & $\begin{array}{l}\text { Observer } \\
\text { Index }\end{array}$ \\
\hline $\begin{array}{l}1.0 \\
0.2 \\
0.1-0.3 \\
0.1 .0 \\
0.9\end{array}$ & $\begin{array}{l}\text { Ball } \\
\text { Koprov \& Tsvang } \\
\text { Deardorff } \\
\text { Lilly } \\
\text { Lenschow \& Johnson }\end{array}$ & $\begin{array}{l}1960 \\
1965 \\
1967 \\
1968 \\
1968\end{array}$ & $\begin{array}{l}\text { QJRMS } \\
\text { JAM } \\
\text { QJRMS } \\
\text { JAM }\end{array}$ & $\begin{array}{l}\mathbf{T} \\
0 \\
0 \\
\mathrm{~T} \\
0\end{array}$ & $\begin{array}{l}1 \\
2 \\
3 \\
4 \\
5\end{array}$ \\
\hline $\begin{array}{l}0.12 \text { avg. } \\
<1.0 \\
0.1 \\
0.1 \\
0.15\end{array}$ & $\begin{array}{l}\text { Deardorff, Willis \& Lilly } \\
\text { Geisler \& Kraus } \\
\text { Lenschow } \\
\text { Deardorff } \\
\text { Stull }\end{array}$ & $\begin{array}{l}1969 \\
1969 \\
1970 \\
1972 \\
1973\end{array}$ & $\begin{array}{l}\text { JFM } \\
\text { DSR } \\
\text { JAM } \\
\text { MWR } \\
\text { JAS }\end{array}$ & $\begin{array}{l}0 \\
\mathrm{~T} \\
0 \\
0 \\
\mathrm{~T}\end{array}$ & $\begin{array}{r}6 \\
7 \\
8 \\
9 \\
10\end{array}$ \\
\hline $\begin{array}{l}0.13 \\
-0.04-0.17 \\
<0.1 \\
0.2 \\
0.2\end{array}$ & $\begin{array}{l}\text { Deardorff } \\
\text { Lenschow } \\
\text { Stull } \\
\text { Deardorff } \\
\text { Tennekes }\end{array}$ & $\begin{array}{l}1973 \\
1973 \\
1973 \\
1973 \\
1973\end{array}$ & $\begin{array}{l}\text { JAS } \\
\text { JAS } \\
\text { (NCAR) } \\
\text { JAS } \\
\text { JAS }\end{array}$ & $\begin{array}{l}T \\
0 \\
0 \\
0 \\
T\end{array}$ & $\begin{array}{l}11 \\
12 \\
13 \\
14 \\
15\end{array}$ \\
\hline $\begin{array}{l}0-0.5 \\
0.25 \\
0.25 \\
0.5-2.0 \\
<0.12\end{array}$ & $\begin{array}{l}\text { Carson } \\
\text { Betts } \\
\text { Carson } \\
\text { Coulman } \\
\text { Lenschow }\end{array}$ & $\begin{array}{l}1973 \\
1973 \\
1973 \\
1973 \\
1974\end{array}$ & $\begin{array}{l}\text { QJRMS } \\
\text { QJRMS } \\
\text { QJRMS } \\
- \\
\text { JAS }\end{array}$ & $\begin{array}{l}0 \\
0 \\
T \\
0 \\
0\end{array}$ & $\begin{array}{l}16 \\
17 \\
18 \\
19 \\
20\end{array}$ \\
\hline $\begin{array}{l}<0.10 \\
0.21 \\
0.17 \\
0.20 \\
0.19\end{array}$ & $\begin{array}{l}\text { Pennell \& LeMone } \\
\text { Deardorff } \\
\text { Deardorff } \\
\text { Deardorff } \\
\text { Deardorff }\end{array}$ & $\begin{array}{l}1974 \\
1974 \\
1974 \\
1974 \\
1974\end{array}$ & $\begin{array}{l}\text { JAS } \\
\text { BLM } \\
\text { BLM } \\
\text { BLM } \\
\text { BLM }\end{array}$ & $\begin{array}{l}0 \\
T \\
T \\
T \\
T\end{array}$ & $\begin{array}{l}21 \\
22 \\
23 \\
24 \\
25\end{array}$ \\
\hline $\begin{array}{l}0.14 \\
0.23 \\
0.29 \\
0.32 \\
0.25\end{array}$ & $\begin{array}{l}\text { Deardorff } \\
\text { Stull } \\
\text { Cattle } \varepsilon \text { Weston } \\
\text { Cattle } \& \text { Weston } \\
\text { Rayment } \varepsilon \text { Readings }\end{array}$ & $\begin{array}{l}1974 \\
1974 \\
1974 \\
1974 \\
1974\end{array}$ & $\begin{array}{l}\text { BLM } \\
- \\
\text { QJRMS } \\
\text { QJRMS } \\
\text { QJRMS }\end{array}$ & $\begin{array}{l}T \\
T \\
0 \\
0 \\
0\end{array}$ & $\begin{array}{l}26 \\
27 \\
28 \\
29 \\
30\end{array}$ \\
\hline $\begin{array}{l}0.23 \\
0.30 \\
0.11-0.23 \\
0.2 \\
0.2-0.5\end{array}$ & $\begin{array}{l}\text { Deardorff, Willis \& Lilly } \\
\text { Betts } \\
\text { Willis \& Deardorff } \\
\text { Sarachik } \\
\text { Tennekes \& Van Ulden }\end{array}$ & $\begin{array}{l}1974 \\
1974 \\
1974 \\
1974 \\
1975\end{array}$ & $\begin{array}{l}\text { QJRMS } \\
\text { QJRMS } \\
\text { JAS } \\
\text { JAS } \\
\quad-\end{array}$ & $\begin{array}{l}\text { OT } \\
\text { OT } \\
0 \\
T \\
0\end{array}$ & $\begin{array}{l}31 \\
32 \\
33 \\
34 \\
35\end{array}$ \\
\hline
\end{tabular}

should be applicable to most atmospheric inversion rise situations, problems do occur when $\Delta \theta_{v} \approx 0$. However, it is easy to re-derive the energetics equation with a more general description of the potential energy term that includes the lapse rate above the inversion base. For example, (5) becomes

$$
\delta h\left(\Delta \theta_{v}+\gamma \delta h / 2\right)=\frac{2 \theta_{v 0}}{g d_{1}}\left[c_{1} w_{*}^{3}+c_{2} u_{*}{ }^{3}+c_{3}\left(\Delta u_{h}\right)^{3}-\mathrm{GW}\right] \delta t,
$$

where $\delta h / \delta t \equiv w_{e}$.

\section{Comparison with existing theories and laboratory experiments}

It is interesting to recognize that the energetics theory derived here reduces, for special cases, to forms similar with previously published theories and labora- tory experiments. Such a comparison is made next for the special cases of free convection, forced convection, and for wind shear across the density step.

a. Free convection $\left[u_{*}, \Delta u_{h}, G \dot{W}=0\right]$

Tennekes (1973), Betts (1973) and Carson (1973) have assumed the entrainment rate is such that

$$
-\left(\overline{w^{\prime} \theta_{v}^{\prime}}\right)_{h}=A_{1}\left(\overline{w^{\prime} \theta_{v}^{\prime}}\right)_{s}
$$

when wind speeds and gravity wave losses are small. Using (4), one sees that the energetics relation (7) reduces to this same result for free convection. Most of the published values for $A_{1}$ lie between 0.1 and 0.3 , although values ranging from zero to unity have appeared (see Table 1 and Fig. 2) 
Stull (1973) modeled the entrainment rate as the distance $d$ of overshoot of the penetrative convection divided by the time $t_{*}$ between occurrences of overshoot over a unit area:

$$
w_{e}=\frac{1}{2} \frac{d}{t_{*}}
$$

Then using his other assumptions, viz.,

$$
\left.\begin{array}{l}
d \approx 0.4 w_{*} / N \\
t_{*} \approx 0.35 h / w_{*} \\
N \approx\left(\frac{g}{\theta_{v_{0}}} \frac{\Delta \theta_{v}}{d}\right)^{\frac{\lambda}{2}}
\end{array}\right\},
$$

one finds that (9) becomes

$$
w_{e}=0.23 \frac{w_{*}^{3}}{g\left(\Delta \theta_{v} / \theta_{v 0}\right)_{h}}=0.23 \frac{\overline{\left(w^{\prime} \theta_{v}^{\prime}\right)_{s}}}{\Delta \theta_{v}},
$$

which is also similar to the energetics theory (7) when winds and gravity wave losses are small, for $A_{1}=0.23$.

\section{b. Forced convection $\left[\left(\overline{w^{\prime} \theta_{v}^{\prime}}\right)_{s}, \Delta u_{h}, G \dot{W}=0\right]$}

Rouse and Dodu (1955) were the first investigators to note that the entrainment rate should be inversely proportional to the Richardson number if the potential energy change associated with entrainment is proportional to the rate of work done $\mathrm{cn}$ the fluid. This result was observed in the tank experiments of Kato and Phillips (1969) and Wu (1973) in which a shear stress was applied to the mixed layer, and in some of the grid stirring experiments of Cromwell (1960), Turner (1968a, b) and Wolanski and Brush (1975).
The energetics equation (5) yields the same result for forced convection, i.e.,

$$
\frac{w_{e}}{u_{*}}=2 c_{2}\left[\frac{g\left(\Delta \theta_{v} / \theta_{v 0}\right) d_{1}}{\left(u^{*}\right)^{2}}\right]^{-1} \propto 2 c_{2} \mathrm{Ri}_{B}{ }^{-1},
$$

where $d_{1}=h$ for no surface heating.

c. Wind shear and dynamic instabilities at the interface

$$
\left[\left(\overline{w^{\prime} \theta_{0}^{\prime}}\right)_{s}, u_{*}, G \dot{W}=0\right]
$$

For this special case, the experiments of Ellison and Turner (1959), Lofquist (1960), Moore and Long (1971) and Thorpe (for the later stages of growth of Kelvin-Helmholz waves and the ensuing turbulence) also indicate that the entrainment is inversely proportional to the Richardson number:

$$
\frac{w_{e}}{\Delta u_{h}} \propto\left[\frac{g\left(\Delta \theta_{v} / \theta_{v 0}\right) d_{1}}{\left(\Delta u_{h}\right)^{2}}\right]^{-1} \propto \mathrm{Ri}_{B}{ }^{-1} .
$$

This same result is obtained from the energetics theory (7).

\section{d. General cases}

In general, real atmospheric or oceanic situations cannot be described by any one of the special cases shown here because many of the turbulence generating mechanisms are operating simultaneously. Hence, either interpolation formulas combining more than one of the special cases (Tennekes, 1973; Deardorff, 1974a) or the full energetics theory ( 7 ) should be used. A test of the full energetics theory is made in a companion paper (Stull, 1976b), with very good results.

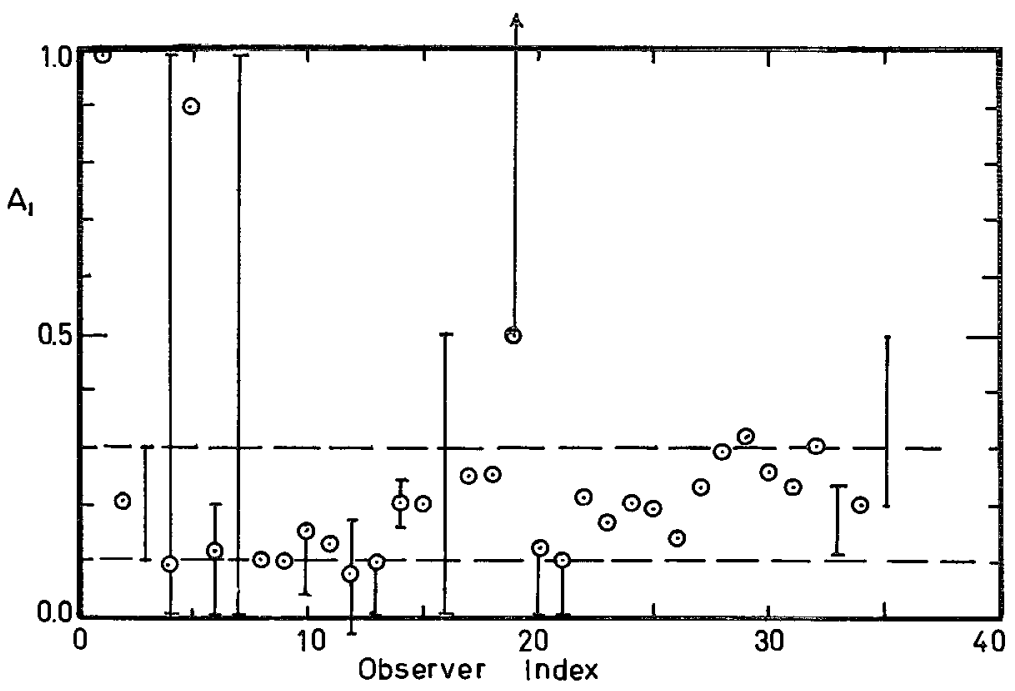

Fig. 2. Graph showing the published values of the ratio $A_{1}$ of downward heat flux at the inversion base to upward heat flux at the earth's surface. The observer index is listed in Table 1. 


\section{Values of the coefficients}

The value of each coefficient in the energetics entrainment equation is restricted to lie within the ranges of previously published values as found from the laboratory and field experiments described in the special cases of Section 4 . These ranges are as follows:

$\begin{array}{llll}0.1 & \leqslant A_{1} \leqslant 0.3 & 0.910 \leqslant b_{1} \leqslant 0.990 & 0.005 \leqslant c_{1} \leqslant 0.035 \\ 0.01 \leqslant A_{2} \leqslant 0.22 & 0.890 \leqslant b_{2} \leqslant 0.995 & 0.23 \quad \leqslant c_{2} \leqslant 2.9 \\ 0.0008 \leqslant A_{3} \leqslant 0.01 & 0.90 \leqslant b_{3} \leqslant 0.99 & 4 \times 10^{-4} \leqslant c_{3} \leqslant 5 \times 10^{-3}\end{array}$

By testing the full energetics theory against several real atmospheric cases of inversion rise (Stull, 1976b) and determining the best values of the coefficients within the specified ranges by trial and error (where the "best" value gives the closest agreement between predicted and observed inversion rise), it is found that:

$$
\begin{array}{lll}
A_{1}=0.10 & b_{1}=0.990 & c_{1}=0.005 \\
A_{2}=0.05 & b_{2}=0.975 & c_{2}=0.5 \\
A_{3}=0.001 & b_{3}=0.985 & c_{3}=0.0006
\end{array}
$$

Note that the best values of the coefficients $A_{1}, A_{2}, A_{3}$ fall in the smaller side of their respective ranges. This reflects the fact that the experimenters were unable to completely eliminate all but one of the turbulence generation or loss mechanisms. For example, atmospheric observations made when free and forced convection existed simultaneously were sometimes unjustifiably assumed to be free convection only.

\section{Summary and conclusions}

The potential energy change per unit area due to turbulent entrainment (of warm air downward in the atmospheric case) is related to the turbulent kinetic energy equation integrated over the depth of the mixed layer. By applying this to an idealized slab-like mixed layer model, some simplifications and approximations can be made to yield an entrainment rate equation (the energetics theory).

Many previously published theories and laboratory experiments are shown to be similar to special cases of the energetics theory. Hence, the energetics entrainment equation $[(5),(6)$ or $(7)]$ is offered as a closure equation to be used in mixed layer models. Such an application to the atmospheric situation of a temperature inversion capping a turbulent mixed layer is made by Stull (1976b), with very good results.

Acknowledgments. ${ }^{3}$ Deep thanks goes to my mentor, Joost A. Businger, for his guidance, criticisms, and patient understanding. I also benefitted from discussions with Paul Arya, Robert Fleagle, John Booker, James Deardorff, Edward Zipser, Margaret LeMone and William Pennell. The research was conducted mostly with the Planetary Boundary Layer group at the Department of Atmospheric Sciences, University

\footnotetext{
${ }^{3}$ These acknowledgments also apply to the companion papers in this series.
}

of Washington, funded by the National Science Foundation under Grant DES74-00964 A01 (formerly GA40648X). An NSF traineeship also funded me during my first year of work. I also gratefully acknowledge my association with the National Center for Atmospheric Research (sponsored by NSF) through the GATE group and as a summer fellow in scientific computing.

\section{REFERENCES}

Baines, W. D., 1975 : Entrainment by a plume or jet at a density interface. $J$, Fluid Mech., 68, 309-320.

Ball, F. K:, 1960: Control of inversion height by surface heating. Quart J. Roy. Meteor. Soc., 86, 43-494.

Betts, A. K., 1973 : Non-precipitating cumulus convection and its parameterization. Quart. J. Roy. Meteor. Soc., 99, 178-196.

, 1974: Reply to comments on "Non-precipitating cumulus convection and its parameterization." Quart.J. Roy. Meteor. Soc., 100, 469-471.

Businger, J. A., J. C. Wyngaard, Y. Izumi and E. F. Bradley, 1971 : Flux-profile relations in the atmospheric surface layer. $J$. Atmos. Sci., 28, 181-189.

Carson, D. J., 1973: The development of a dry inversion-capped convectively unstable boundary layer. Quart. J. Roy. Meteor. Soc., 99, 450-467.

Cromwell, T, 1960: Pycnoclines created by mixing in an aquarium tank. J. Marine Res., 18, 73-82.

Deardorff, J. W., 1973: An explanation of anomalously large Reynolds stresses within the convective planetary boundary layer. J. Atmos. Sci., 30, 1070-1076.

- $174 \mathrm{a}$ : Three-dimensional numerical study of the height and mean structure of a heated planetary boundary layer. Boundary-Layer Meteor., 7, 81-106.

-, $1974 \mathrm{~b}$ : Three-dimensional numerical study of turbulence in an entraining mixed layer. Boundary-Layer Meteor., 7, 199226.

- G. E. Willis and D. K. Lilly, 1969: Laboratory investigation of non-steady penetrative convection. J. Fluid. Mech., 35, 7-31.

Drake, R. L., P. D. Coyle and D. P. Anderson, 1975 : Interactive line thermals in a convective layer: A numerical simulation. J. Atmos. Sci., 32, 302-319.

Dyer, A. J., 1974: A review of flux-profile relationships. BoundaryLayer Meteor., 7, 363-372.

Ellison, T. H., and J. S. Turner, 1959: Turbulent entrainment in stratified flows. J. Fluid Mech., 6, 423-448.

Fleagle, R. G., and J. A. Businger, $1963:$ An Introduction to Atmospheric Physics. Academic Press, 129-179.

Geisler, J. E., and E. B. Kraus, 1969: The well-mixed Ekman boundary layer. Deep-Sea Res., 16, Suppl., 73-84.

Jones, W. L., 1969: The transport of energy by internal waves. Tellus, 21, 177-184:

Kato, H., and O. M. Phillips, 1969: On the penetration of a turbulent layer into stratified fluid. $J_{6}$ Fluid Mech., 37, 643-655.

Kraus, E. B., and J. S. Turner, 1967 : A one-dimensional model of the seasonal thermocline. Part II. The general theory and its consequences. Tellus, 19, 98-105.

Lenschow, D. H., 1974: Model of the height variation of the turbulent kinetic energy budget in the unstable planetary boundary layer. $J$. Atmos. Sci., 31, 465-474.

Lilly, D. K., 1968: Models of cloud-topped mixed layers under a strong inversion. Quart. J. Roy. Meteor. Soc., 94, 292-309.

Lofquist, K., 1960: Flow and stress near an interface between stratified liquids. Phys. Fluids, 3, 158-175.

Miropol'skiy, Y. A., 1970: Nonstationary model of the wind-convection mixing layer in the ocean. Izv. Atmos. Oceanic Phys., 6, 1284-1294. 
Moore, N. J., and R. R. Long, 1971 : An experimental investigation of turbulent stratified shearing flow. J. Fluid Mech., 49, 635655.

Niiler, P. O., 1976: Deepening of the wind-mixed layer. J. Marine Res. (in press).

Paulson, C. A., 1970: The mathematical representation of wind and temperature profiles in the unstable surface layer. $J$. Appl. Meteor., 9, 857-861.

Pollard, R. T., P. B. Phines, and R. O. R. Y. Thompson, 1973: The deepening of the wind-mixed layer. Geophys. Fluid Dyn., 3, 381-404.

Rouse, H., and J. Dodu, 1955: Turbulent diffusion across a density discontinuity. Honille Blanche, 10, 522-532.

Stull, R. B., 1973 : Inversion rise model based on penetrative convection. J. Atmos. Sci, 30, 1092-1099.

,$- 1976 a$ : Internal gravity waves generated by penetrative convection. J. Atmos. Sci., 33, 1279-1286.
- $1976 \mathrm{~b}:$ Mixed layer depth model based on turbulent energetics. J. Atmos. Sci., 33, 1268-1278.

Tennekes, H., 1973: A model for the dynamics of the inversion above a convective boundary layer. J. Almos. Sci., 30, 558567.

Thorpe, S. A., 1973 : Experiments on instability and turbulence in a stratified shear flow. J. Fluid Mech., 61, 731-751.

Turner, J. S., 1968a: The behavior of a stable salinity gradient heated from below. J. Fluid Mech., 33, 183.

- $1968 \mathrm{~b}$ : The influence of molecular diffusivity on turbulent entrainment across a density interface. $J$. Fluid Mech., 33, 639.

Wolanski, E. J., and L. M. Brush, Jr., 1975: Turbulent entrainment across stable density step structures. Tellus, 27, 259-268.

Wu, J., 1973: Wind-induced turbulent entrainment across a stable density interface. I. Fluid Mech., 61, 275-287.

Wyngaard, J. C., and O. R. Coté, 1974: The evolution of a convective boundary layer-A higher order closure model study. Boundary-Layer Meteor., 7, 289-308. 